\title{
Flipped teaching and interactive tools. A multidisciplinary innovation experience in higher education
}

\author{
Jesús Sergio Artal-Sevil ${ }^{1}$, Ana Felicitas Gargallo Castel $^{2}$, Marta Sofía Valero Gracia ${ }^{3}$ \\ ${ }^{1}$ Department of Electrical Engineering. Escuela de Ingeniería y Arquitectura, EINA, \\ University of Zaragoza, Spain, ${ }^{2}$ Department of Business Management. Faculty of Social \\ and Human Sciences, University of Zaragoza, Spain, ${ }^{3}$ Department of Pharmacology and \\ Physiology. Faculty of Health Sciences and Sports, University of Zaragoza, Spain.
}

\begin{abstract}
Nowadays learning methods in higher education are under a constant review process. Applications focused on Blended-Learning allow to speed-up the learning process; this facilitates the design and implementation of interactive resources in the classroom. The present study shows an experience developed with engineering master students. Flipped Teaching approach has achieved significant mention in academic circles in recent years. Undoubtedly, the implementation of this educational methodology improves students' motivation and increases their participation in the classroom.

In this paper different Information and Communication Technologies (ICT) tools and multimedia resources that facilitate the teaching sessions are presented. Its use has been simple and intuitive. These educational tools increase the skills, abilities and competences acquired by students. The objective is to achieve more interactive learning. Students positively value this activities related to the Flipped Learning. In addition, students prefer teaching-learning procedures more dynamic, flexible, creative, participatory and with continuous evaluation. Although the general impression is that they need more effort and more dedication, compared to the Traditional Teaching. Every time there is a greater number of educational tools and electronic devices for higher education. However, its use must be correct so that it can be useful in training students.
\end{abstract}

Keywords: Flipped Teaching; Blended Learning; Game-based Learning; Advanced Classroom Technology; Interactive Tools. 


\section{Introduction}

Do ICTs help us to make our classes more interactive and collaborative? Is it possible to apply new methodological models supported by technological resources available today? In the last few years, mobile devices as laptops, tablets, e-books and smartphones became more and more popular. Every time there is a larger number of resources and devices destined for his utilization in education (Artal-Sevil \& Romero, 2018). Thus a change has occurred in the nature of higher education. The evolution of devices developed for mobile platforms has allowed the introduction of various free applications in the academic field.

Many authors have cited the relevance of ICT in the Flipped pedagogical approach. Thus, Bates and Galloway (2012) or Artal-Sevil (2019) have applied this technique for some years in their educational task. The results were satisfactory. There was an improvement in attitude and student participation. In turn, Roach (2014) described the perceptions during the application of the Flipped Teaching. As shown in the results, students respond positively to the introduction of this new teaching strategy, although it entails an increase in academic activities.

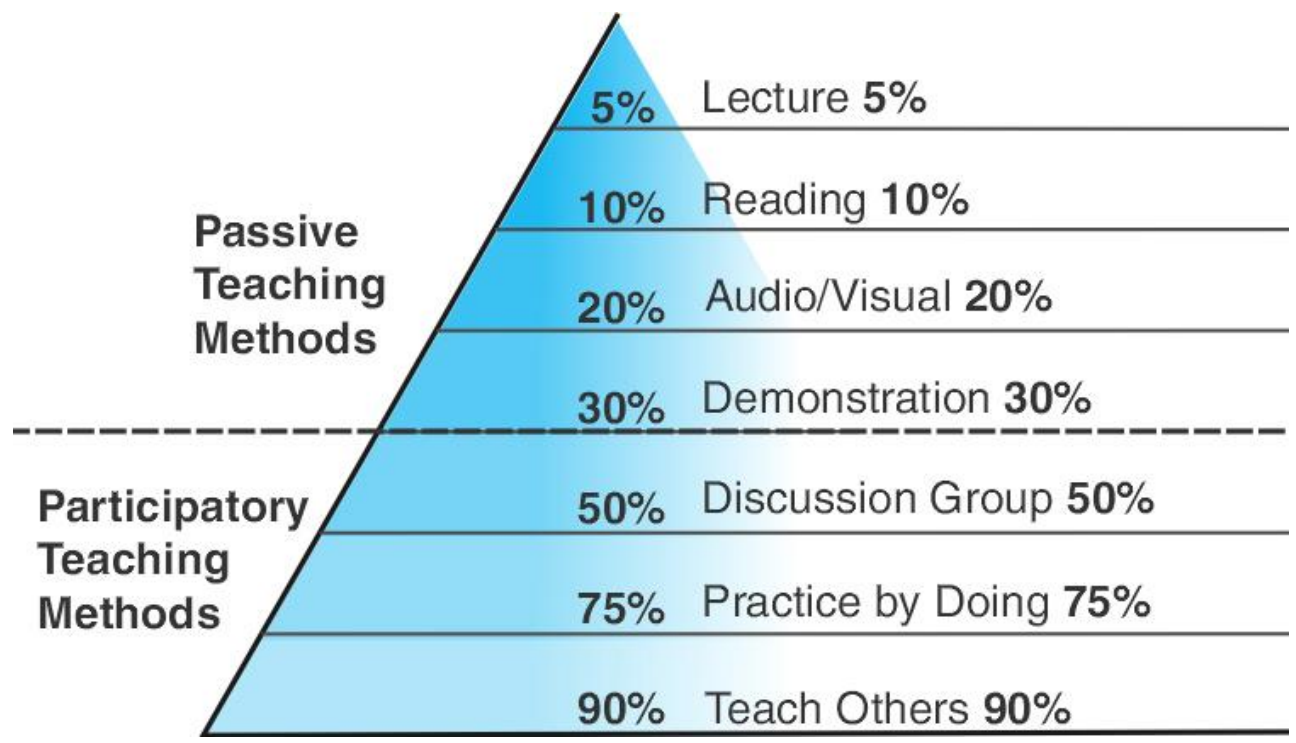

Figure 1. Active and Passive teaching methods. Average retention ratio in students.

On the other hand O'Flaherty and Phillips (2015) developed a deep bibliographical revision and proposed different synchronous and asynchronous activities for their incorporation in the classroom. The results indicate that this strategy increases educational efficiency and provides greater motivation for students. While Cieliebak and Frei (2016) evaluated the influence of the Flipped strategy on the skills acquired by students of engineering with 
respect to classic methodologies. In the study it is possible to appreciate better results on the non-technical competences acquired by the students. In this way, the Flipped Learning strategy is a viable alternative to the traditional procedure. Similarly, García de Oliveira et al. (2014) presented a different educational tools that could help teachers during the implementation of the Flipped Learning model in the classroom. At the same time, they provide some advice on the evaluation and interpretation of results.

The idea has been to introduce the most current technology for students in the university classroom. This integration has a double perspective. On the one hand, to optimize the teaching-learning process, disclose their knowledge and improve student academic training. On the other hand, the use of new technologies in the classroom can significantly increase student interest. Figure 1 shows the pyramid learning. In the image is possible to observe the different learning coefficients (average retention rate) based on the teaching methods (lecture, reading, audio/visual, etc.). The most active and participatory methods have the largest learning coefficients.

\section{Objetives and Educational Context}

In this paper is presented an educational innovation experience based on Flipped Teaching pedagogical approach with the incorporation of active-collaborative activities developed during the academic year 2018/19 in the Master's degree in Renewable Energy and Energy Efficiency, Master's degree in Industrial Engineering and PostGraduate in Renewable Energy Grid Integration. The experience was approached from the perspective of researchaction in teaching team. The main objective has been to improve the use of applications for educational innovation inside and outside the classroom, while student participation is encouraged. At the same time it is possible to contrast the usefulness and effectiveness of the learning strategies. The specific learning objectives set are listed below. All initial objectives were achieved systematically and satisfactorily

- Use new applications, active tools and mechanisms for the continuous supervision of the student. Facilitate the understanding of the concepts and the acquisition of skills and competences associated to the matter.

- Structure the in-class sessions (seminars) and academic activities outside the classroom (webinar). Motivate students during the development of their academic tasks.

- Develop and incorporate different interactive games and Q\&A questionnaires (implementation of the Game-based Learning strategy) as a complement to the Flipped Teaching model. 


\section{Flipped Teaching Model}

Flipped Teaching or inverted class methodology consists in that the students prepare certain learning contents outside the classroom, usually as homework. Thus it is possible to perform other much more practical academic tasks in the classroom. As a result of the incorporation of Flipped Teaching methodology and the introduction of some online tools described in this document, it has been possible to promote a series of educational experiences that enhance the learning process. The use of interactive tools has allowed that the classroom sessions can be more interactive, increasing the motivation of the students. Therefore this method has facilitated interaction and knowledge construction through an active-collaborative learning. Bergmann and Sams (2012) explain that a Flipped Classroom is a classroom with mixed direct instructions that focus on constructing students based on the subject, see figure 2 . The before-class time is dedicated to the study and preparation of the different academic task in order to obtain a previous knowledge. While in-class time it is dedicated to interactive learning and critical thinking processes. This series of activities include the use of mobile devices, quizzes and games (Artal-Sevil, 2020).
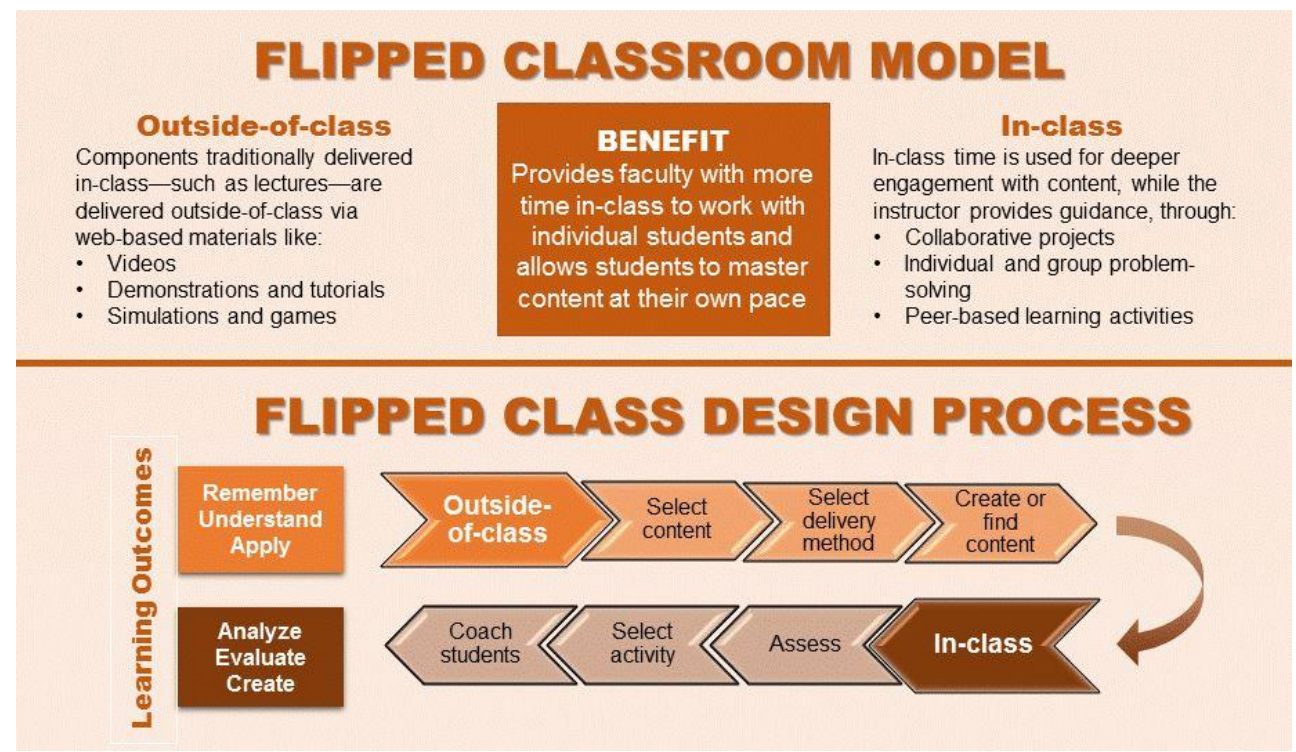

Figure 2. What is the Flipped Classroom? A "flipped class" is a classroom where the typical cycle of content acquisition is reversed.

The objective is to enhance learning and deepen specific content and materials. Therefore, the activities performed in class, are more related to problem solving, collaborative activities or group discussion. These activities are totally opposed to the passive approach in the Traditional Teaching; where the protagonist is only the teacher. Thereby the use of ICT tools is essential. The purpose is to improve classroom dynamics and develop 
collaborative learning activities. In summary, the method proposes a student-centered teaching. The student has changed from a passive role to an active role (Kerr, 2015).

Applications focused in Flipped Teaching and Blended-Learning, have allowed to speed-up the learning process. This facilitates the implementation and design of interactive strategies in the classroom. The instructor prepares a session with questions related to the basic knowledge and each student used his own mobile phone to give the answer to the respective question. The results are immediate. In addition, students have instant feedback. The method is based on open-source and easy-to-use tools. There is an increase in motivation, interactivity and personal responsibility. The classroom environment is good and flexible. It is possible to attend different learning rates and respond to the absence of knowledge. Students come to class better prepared. The teacher can also get feedback on the student's knowledge before class. Students can be directed in a more personalized manner. Thereby, the teacher is more useful for the students since in the class time can correct academic tasks and resolve the doubts of students. The ultimate purpose is to consolidate learning.

\section{Interactive Tools}

ICT tools used in this experience involve the incorporation of free apps and free software as learning support. These applications are used in the implementation of active strategies in the classroom, as Flipped Learning. But other strategies have also been used: Problembased Learning, Game-based Learning, Simulation-based Learning, Learning-by-doing, Puzzle-based Learning, Blended-Learning..., as complement to Flipped Classroom. This methodology has a pedagogical effectiveness superior to the traditional system. Students can learn more and better (Artal-Sevil, 2020). Multimedia resources and ICT tools provide the necessary mechanisms to implement a good educational innovation. 


\section{En un dispositivo que opera en modo conmutación ZCS/ZVS...}

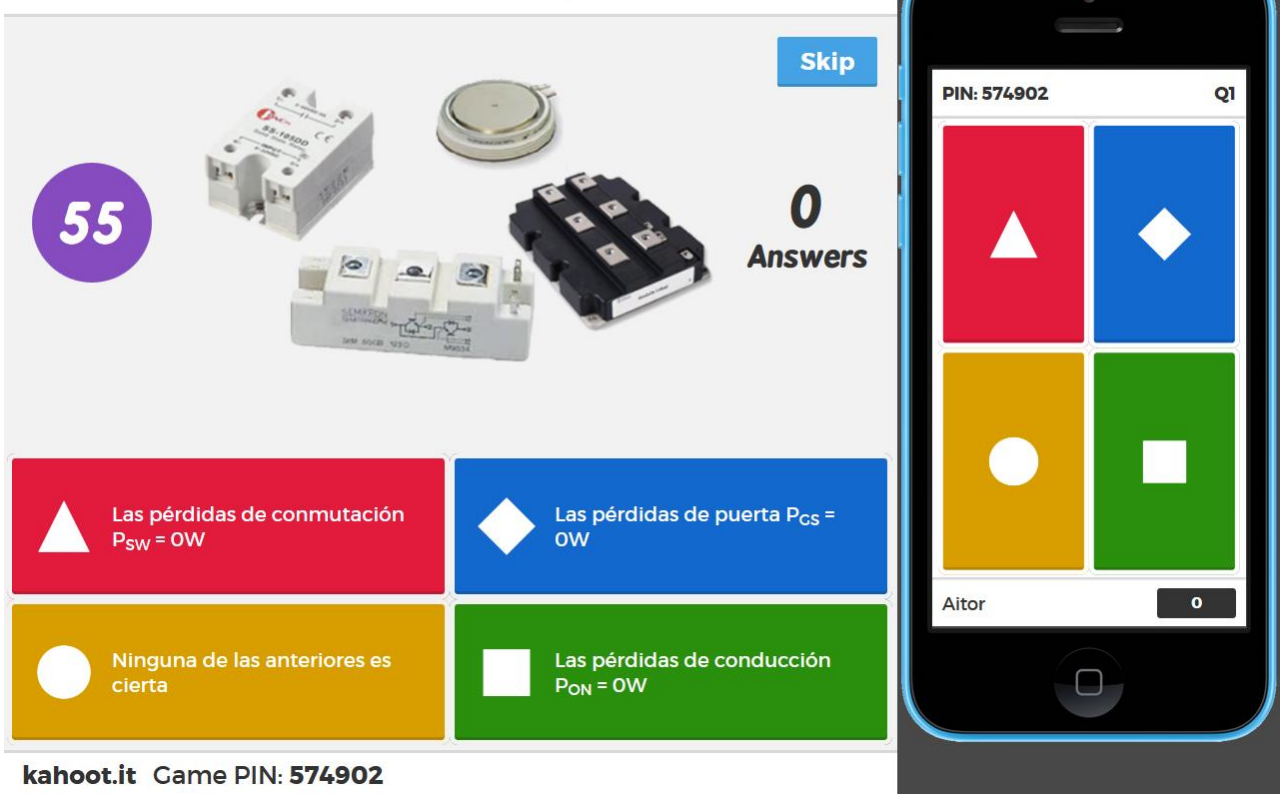

Figure 3. Question \& Answer format developed with free software Kahoot.

Mobile devices were used to evaluate the effects of learning and the interactivity degree. Concept-tests and questionnaires were used to observe the participation and learning coefficient. During class-time different methodologies with interactive question-answers (Q\&A) have been used. Each student has used his own smartphone to respond to the proposed questionnaires. The results are obtained in real time. The use and implementation in the classroom are similar to traditional $i$-clickers (Lucke et al., 2013).

For the in-class activities, different techniques were used such as: resolution questionnaires (test questions); problem resolution and short step by step questions; interactive Q\&A (by Socrative, Kahoot, Quizizz and Plickers software), educational games and small theory-pills (Nearpod). Moodle has also been used as a repository for documents, files and multimedia resources. Furthermore, this platform manages the different academic tasks of the students. It is a fundamental element in the m-learning. Flipped Learning is based on abundant multimedia resources (YouTube videos) and interactive seminars (webinars). All activities are developed sequentially with the theory, seminars and academic tasks. Free software and mobile applications are preferred, especially from the student's view. It is the result of the implementation of the BYOD model (Bring Your Own Device) in higher education. All these ICT tools have made it possible to improve the digital competences of the students. 
Socrative, Kahoot, Quizizz and Plickers are free software applications that can create online questionnaires in order that the students respond in real time (questions and answers) through the mobile device, see figure 3 . The results are obtained immediately and can be shown to students at the end of class. This applications constitute good interactive tools.

Google-Apps (G-Suite) offers a powerful set of tools that can be used to develop collaborative environments between students. The platform has a diverse group of applications that can be used for education, such as Google-Drive, Google-Classroom, Meet, Calendar, Docs, Forms, Slides, etc.

DirectPoll is a free online tool for educational use. This application allows the teacher to interact very easily with the audience during a presentation in the classroom. It is possible to develop the survey in advance or on the fly, incorporating individual questions as well as multiple choice and other options. The public uses a link, provided by the teacher, to vote.

Nearpod is an interactive classroom tool for teachers to engage students with interactive lessons. This free application allows to show small theory presentations (theory-pills) on the smartphone. The platform uses the tablet to manage the content on student's mobile devices. This application combines presentations, collaborative activities, multimedia resources and assessment tools in real time. It is an integrated solution. The application is used to share different contents with students and easily manage the flow of the lesson.

EDpuzzle and PlayPosit are other applications destined to the development of audiovisual materials. These programs allow recording video lessons, fractionate a video and insert questions about the fragments seen recently. These tools are more versatile and can incorporate different multimedia resources. Thereby students watch the video of the lesson carefully because they have to answer a series of questions later. Its use is relatively simple and does not require deep technical knowledge.

\section{Results and Conclusions}

Educational innovation experience here presented is economically sustainable, efficient and transferable to other matters and knowledge disciplines in technical degrees. Several studies indicate that the integration of Flipped Teaching together with e-learning can improve results with a most significant learning. The implemented methodology helps to improve student learning. Thus students have achieved the same level of knowledge than in previous years with other more traditional learning strategies. Student participation and motivation has also been increased. Global satisfaction degree of the students in the development of these experiences has been high. Students prefer teaching-learning procedures more dynamic, flexible, creative and continuous evaluation. Although the general impression is that they require more effort and more dedication, compared to the traditional procedure, 
see figure 4. This paper also shows a series of free tools intended for Flipped Teaching methodology. Its use is simple and intuitive. The degree of student motivation has increased with the introduction of this learning strategy. These educational tools increase the skills, abilities and competences acquired by students.
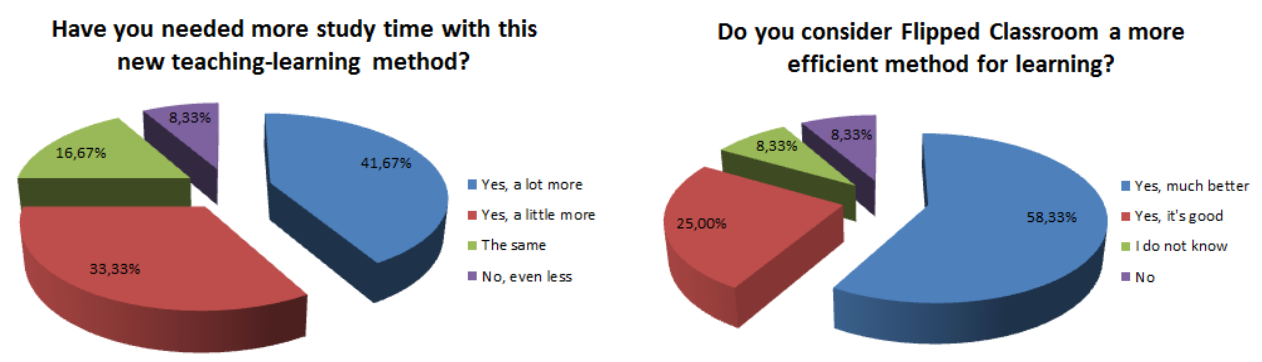

Figure 4. Flipped Teaching model. Survey of student opinion during implementation.

Table 1. Results obtained in the student opinion survey (Likert scale 1-7). Impact analysis of ICT tools on students. Responses obtained in the satisfaction survey in Master of Renewable Energies, Master of Industrial Engineering and PostGraduate in Renewable Energy Grid Integration.

\begin{tabular}{lccc}
\hline Degree/Master & $\begin{array}{c}\text { Master of } \\
\text { Renewable } \\
\text { Energies }\end{array}$ & $\begin{array}{c}\text { Master of } \\
\text { Industrial } \\
\text { Engineering }\end{array}$ & $\begin{array}{c}\text { PostGraduate } \\
\text { in Grid } \\
\text { Integration }\end{array}$ \\
\hline Learning is easier using ICT & 6,071 & 6,243 & 6,127 \\
I like to use ICT in class & 6,571 & 6,563 & 6,234 \\
$\begin{array}{l}\text { The use of applications/ICT generates a lot of } \\
\text { stress }\end{array}$ & 1,357 & 1,247 & 1,216 \\
$\begin{array}{l}\text { It is easy to learn how to use these ICT tools } \\
\text { Working with ICT applications makes me very }\end{array}$ & 6,428 & 6,563 & 6,449 \\
nervous & 1,312 & 1,247 & 1,285 \\
$\begin{array}{l}\text { With ICT I believe that my learning is more } \\
\text { effective }\end{array}$ & 5,933 & 6,017 & 6,234 \\
It is a good idea to use serious-games and ICT tools & 6,437 & 6,326 & 6,453 \\
I feel uncomfortable when I have to use ICT & 1,248 & 1,385 & 1,285 \\
I believe that ICTs are important for my training & 6,571 & 6,127 & 6,332 \\
ICT improves my performance & 5,874 & 6,017 & 6,127 \\
\hline
\end{tabular}


On the other hand, the implementation of the new educational strategy has significantly increased student satisfaction. The willingness of students to use these tools has been very favorable. In order to know the success or failure of the implemented strategy and ICT tools, valuation surveys have been carried out. Table 1 shows the students' opinion about the impact of ICT in the university classroom. This survey is based on the Likert scale 1-7. Several conclusions can be drawn from the data presented in Table 1. In general, engineering students consider themselves qualified in the use of these ICT tools and their use in the classroom is considered successful and very positive. At the same time, they also believe that with the use of these applications their learning is simpler and more effective. It is evident that the new teaching model incorporated in the different subjects, provides learning accepted by the students.

\section{References}

Artal-Sevil J.S. (2020). "Application of serious games in Higher Education. What are they? How, Where and When to use them?". International Technology, Education and Development Conference, INTED'20. IATED Digital Library. Valencia (Spain); pp.: 8641-8654.

Artal-Sevil J.S. (2019). "Flipped Teaching and Game-based Learning in higher education: the Good, the Bad and the Ugly". International Conference of Education, Research and Innovation, ICERI'19. IATED Digital Library. Seville (Spain); pp.: 9271-9280.

Artal-Sevil J.S. \& Romero E. (2018). "Content Curation: What is it? How to apply this technique in higher education? Resources and tools available". International Conference of Education, Research and Innovation, ICERI18. IATED Digital Library. Seville (Spain), November 2018; pp. 5313 to 5323.

Bates S. and Galloway R. (2012). The inverted classroom in a large enrolment introductory physics course: a case study. London: The Higher Education Academy STEM conference.

Bergmann J. and Sams A. (2012). Flip your classroom: Reach every student in every class every day. Eugene, Oregon, USA: International Society for Technology in Education.

Cieliebak M. and Frei A.K. (2016). "Influence of flipped classroom on technical skills and non-technical competences of IT students". Global Engineering Education Conference (EDUCON 2016). IEEExplore Digital Library.

García de Oliveira A., Moreira D., Cruz G. and Barbosa E.F. (2014). "Tools for the flipped classroom model: An experiment in teacher education". Proceedings IEEE Frontiers in Education Conference (FIE14). IEEExplore Digital Library. Madrid (Spain), October 2014; pp. 1 to 8.

Kerr B. (2015). "The flipped classroom in engineering education: A survey of the research". International Conference on Interactive Collaborative Learning (ICL 2015). IEEExplore Digital Library. 20-24 September 2015. Florence (Italy); pp. 815 to 818. 
Lucke T., Keyssner U. and Dunn P. (2013). "The use of a Classroom Response System to more effectively flip the classroom". Frontiers in Education Conference (FIE 2013). IEEExplore Digital Library.

O'Flaherty J. and Phillips C. (2015) "The use of flipped classrooms in higher education: A scoping review". The Internet and Higher Education. Elsevier Science Direct. April 2015; vol. 25, pp.: 85 to 95.

Roach T. (2014). "Student perceptions toward flipped learning: New methods to increase interaction and active learning in economics". International Review of Economics Education. Elsevier Science Direct. September 2014; vol. 17, pp.: 74 to 84. 